\title{
Genocidio y lesa humanidad. La prensa escrita en los juicios por crímenes de estado en Buenos Aires (2006-2015)
}

Genocide and crimes against humanity. The written press in the state crimes trials in Buenos Aires (2006-2015)

\author{
Natalia Croccocrocconatalia@gmail.com
}

http://orcid.org/0000-0001-8647-5506

Centro de Estudios Sobre Genocidio; Universidad Nacional de Tres de Febrero/ Consejo Nacional de Investigaciones Científicas y Técnicas 


\section{Resumen}

El artículo se propone analizar los modos en que los diarios La Nación, Página/12 y Clarín caracterizan los delitos juzgados en el marco de los juicios por los crímenes cometidos por el Estado durante la última dictadura militar (1976-1983) en la provincia de Buenos Aires en el período 2006-2015. Los interrogantes más importantes que atraviesan el desarrollo analítico son: ¿De qué modo caracterizan los diarios a los delitos? ¿Cuáles son los elementos y sentidos predominantes en sus narrativas? ¿Cuál es el estereotipo hegemónico de los diarios vinculado a la narrativa de los delitos?

En función de los interrogantes se analizan las distintas modalidades de caracterización estructuradas en función de la emergencia de los distintos estereotipos que surgen del análisis arqueológico de las fuentes documentales. Esto tiene como finalidad comprender la construcción diferencial de sentidos y fundamentalmente analizar las caracterizaciones hegemónicas construidas por los diarios que darán cuenta del estereotipo predominante de los "delitos" en la narrativa periodística.

Palabras clave: Prensa escrita; juicios contra genocidas; delitos.

Abstract

The article aims to analyze the ways in which the newspapers La Nación, Página/12 and Clarín characterize the crimes judged in the context of the trials for state crimes committed during de last dictatorship (1976-1983) in the province of Buenos Aires in the period 2006-2015. The most important questions that go through analytical development are: How do newspapers characterize crimes? What are the predominant elements and senses in the narratives? Which is the hegemonic stereotype of the newspapers linked to the narrative of crimes?

Linked to the main questions, the different characterization modalities structured according to the emergence of the different stereotypes that arise from the archaeological analysis of the documentary sources are analysed. The purpose of this is to understand the differential construction of meanings and fundamentally analyze the hegemonic characterizations constructed by newspapers that will account for the predominant stereotype of "crimes" in journalistic narrative.

Key words: Written press; trials against genocidals; crimes. 
En 2005, en Argentina se inicia un proceso de juzgamiento penal a gran escala hacia los responsables y ejecutores del genocidio perpetrado durante la última dictadura militar (1). Esta instancia fue posible luego de la anulación en 2003 de las Leyes de Punto Final (1986) y Obediencia Debida (1987) (2) y la posterior declaración de inconstitucionalidad de las mismas por parte de la Corte Suprema de Justicia de la Nación en 2005. Desde el comienzo del proceso, la prensa escrita ha realizado una cobertura de los juicios de forma sistemática. Este artículo se propone analizar y describir los modos en que los periódicos La Nación, Página/12 y Clarín han caracterizado a este proceso centrando el análisis en las formas en que los periódicos caracterizan a los delitos juzgados.

Se parte del concepto de estereotipo del lingüista Maillo Salgado (1980) para el abordaje analítico de las fuentes periodísticas. Esta noción permite afrontar el objeto de estudio desde una perspectiva que privilegia los sentidos nucleados en la figura de los delitos juzgados en los juicios contra genocidas. Son construcciones discursivas que a partir de determinados sentidos configuran cosmovisiones que delinean valores y cualidades referidos a determinados temas, figuras o sujetos. Se vinculan al orden del conocimiento ya que a partir de determinadas narrativas o referencias describen e intentan comprender: se corresponden a diversos modos de ver y de ser en el mundo que se encuentran condicionados por la actualidad histórica, política y social de las narrativas sobre determinados hechos o temáticas (Maillo Salgado, 1980). De este modo, a partir de la estereotipación, los discursos periodísticos pueden disputar el sentido sobre los modos de nombra, describir y comprender los hechos juzgados en los juicios.

La búsqueda y reconstrucción de la figura de los delitos y su estereotipo predominante se realiza a partir de los discursos periodísticos de todos los artículos y editoriales de Clarín, Página/12 y La Nación en el período 2006-2015. Por discurso se entiende el cúmulo de enunciados dependientes de un mismo sistema de formación (Foucault, 2004: 141). Respecto a la figura aquí analizada, el "sistema de formación" corresponde a los discursos relacionados a los crímenes cometidos por el estado en el período 1975-1983 en el marco de los juicios tal como son narrados por los diarios y que se conectan a distintos modelos explicativos. En ellos los delitos son narrados y expuestos de diversos modos conformando un conjunto de reglas que hacen posible su emergencia y que son abordados en clave arqueológica (Foucault, 2004) retomando el concepto de "archivo" como la ley de lo que puede ser dicho (2004: 170), es decir como lo que se puede decir, que marca las posibilidades de poder decir algo.

Este conjunto de lo dicho sobre los delitos y sus estereotipos se realiza sobre un corpus documental constituido por todas las publicaciones de Clarín, Página/12 y La Nación sobre un conjunto específico de once juicios elegidos intencionalmente dentro de los cuarenta realizados 
en el período 2006-2015 y que aspiran a ser un corpus cabal en lo que refiere a distintos juicios juzgados. La elección corresponde a que son casos distintivos y originales para representar la totalidad del trabajo de archivo que aspiran a abordar distintas características de los mismos. Los juicios penales tienen como objetivo fundamental establecer la responsabilidad de una persona respecto a un delito, pero los delitos que se juzgan en estas instancias judiciales son de un carácter distinto ya que es el mismo Estado quien los cometió. El interés del análisis radica en dar cuenta de qué modo las fuentes analizadas prestan atención a esta especificidad y los modos en que son construidos sus relatos hegemónicos; si a partir de explicaciones que implican lógicas individuales o procesuales. Teniendo en cuenta esta doble particularidad se propone analizar la tensión entre las lógicas individuales de la responsabilidad y los modos de comprensión más integrales de dar sentido a los crímenes de Estado a la luz del trabajo de archivo. El observable son los delitos desde una perspectiva amplia que oscila entre la emergencia de narrativas que los estereotipan a partir de explicaciones individuales, de delitos puntuales y narrativas en donde a los hechos se le asignan explicaciones causales más generales. El repertorio de los crímenes presentados por La Nación, Página/12 y Clarín da cuenta de esta diversidad de caracterizaciones y está conformado casi exclusivamente por dos tipos de crímenes: los de lesa humanidad y el genocidio. A su vez, estos se encuentran atravesados por una lógica de comisión de delitos individuales que describen a la lesa humanidad o al genocidio. Teniendo en cuenta esta tensión, en los siguientes apartados se desarrollan las categorías que conforman la caracterización de los delitos. Para ello, retomando la idea de estereotipo (Maillo Salgado, 1980) y la noción de archivo (Foucault, 2004) se parte de un gesto foucaultiano, el de construcción del objeto, considerando al mismo como algo que no se encuentra dado sino que es una construcción (Foucault, 2004): la propuesta es reponer el objeto "delitos" a partir de una reconstrucción que da cuenta exhaustivamente de los modos de dotarlos de sentido y de extraer su estereotipo (3); es decir el modo hegemónico en que se los caracteriza, en los juicios desarrollados en la provincia de Buenos Aires en el período de tiempo 2006-2015.

\section{Los crímenes de lesa humanidad}

Desde el inicio del proceso de juzgamiento en la provincia de Buenos Aires -en junio de 2006emerge con fuerza un modo de identificar a los delitos que se mantendrá hasta el final del período de tiempo objeto del artículo. Esta identificación es la de "crímenes" o "delitos de lesa humanidad" que, si bien en muchas de las publicaciones suele estar acompañada por otros 
modos de caracterización, es la que mayor predominancia adquiere a lo largo de todo el marco temporal. Aunque es la modalidad con la que más frecuencia se nombra a los delitos, resulta la menos desarrollada en lo que hace a su explicación; los diarios poco indagan y reponen sobre lo que son. Esta es una característica común al tratamiento de los tres periódicos; son los que más veces aparecen nombrados, pero sin una explicación sobre lo que son y lo que implican. Sus implicancias se dan por sentado haciendo que el rastreo de los principales sentidos en los discursos requiera de una reconstrucción extra a la del resto de las caracterizaciones.

Esta reposición sobre los crímenes de lesa humanidad resulta fundamental debido a que a lo largo de diez años de crónicas periodísticas no hay artículos que desarrollen sobre los elementos constitutivos de los mismos. Desde el inicio del proceso se da por sentado lo que son, como si fueran fenómenos conocidos por todos los lectores. Esta constituye la principal característica hallada respecto a los modos de narrar a estos crímenes (4). Esta característica se observa en los tres diarios desde el inicio del proceso. Resulta llamativo que ni siquiera al comenzar el primero de los juicios -contra Miguel Osvaldo Etchecolatz (5)- luego de la anulación de las leyes de impunidad se realice un repaso sobre lo que estos crímenes implican, sino que se los califica como delitos de lesa humanidad dándolos por sentado. En esta dirección se presentan algunos ejemplos de las primeras crónicas sobre este juicio:

\footnotetext{
El represor de la Policía Bonaerense Miguel Osvaldo Etchecolatz se negó a declarar hoy en el juicio en su contra por delitos de lesa humanidad que comenzó en la ciudad de La Plata, argumentando que el proceso debe ser sustanciado por la justicia militar ( Página/12, 20/06/2010).
}

Con la presencia de militantes de organizaciones de derechos humanos en la sala y con algunas interrupciones se realizó hoy la primera audiencia del juicio oral contra el ex director de Investigaciones de la policía bonaerense Miguel Etchecolatz, acusado de cometer delitos de lesa humanidad durante la última dictadura militar (La Nación, 20/06/2010).

El Tribunal Oral Federal 1 de La Plata que lleva adelante el juicio al ex director de investigaciones de la Policía bonaerense, Miguel Etchecolatz, por delitos de lesa humanidad, cumplió hoy con la primera jornada de testimonios de testigos. En total, son más de cien los citados (Clarín, 20/06/2010).

Estos extractos pertenecen a las crónicas de los primeros días de audiencia del juicio a Miguel Osvaldo Etchecolatz. En todos ellos los crímenes que se juzgan son mencionados del mismo 
modo: "delitos de lesa humanidad". Más allá de esta nominación compartida, ninguno de los tres periódicos destina un espacio en su redacción para explicar qué son estos crímenes objeto del proceso judicial ni tampoco cuáles son los elementos, lógicas y procesos que constituyen que sean de "lesa humanidad". Esto no sucede antes ni durante el transcurso de este primer juicio, pero tampoco en los posteriores. A falta de desarrollo explicativo, lo que sí se encuentra en el caso de estos tres artículos es la enumeración de una serie de delitos individuales que se conectan indirectamente con esta categoría, dando por sentado que de ello se tratarían los delitos de lesa humanidad:

Etchecolatz afronta cargos por el homicidio calificado de Diana Esmeralda Teruggi; la privación ilegal de la libertad, torturas y muerte de Patricia Dell'Orto, Ambrosio De Marco, Nora Formiga, Elena Arce y Margarita Delgado; y la privación ilegal de la libertad y torturas de Nilda Emma Eloy y Jorge Julio López (Página/12, 20/06/2010).

El proceso es sustanciado por el Tribunal Oral Federal 1 de La Plata, que enjuicia al ex policía por su responsabilidad en seis homicidios, privaciones ilegales de la libertad y tormentos aplicados a prisioneros durante la dictadura del período 1976-83 (La Nación, 20/06/2010).

Etchecolatz está acusado del homicidio de Diana Teruggi y la privación ilegal de la libertad, torturas y homicidio de Ambrosio Francisco De Marco, Patricia Graciela Dell'Orto, Elena Arce Sahores, Nora Livia Formiga y Margarita Delgado, además del secuestro y tormentos aplicados a Nilda Eloy y Jorge Julio López (Clarín, 22/06/2010).

Los delitos de lesa humanidad que se enuncian al inicio de cada uno de artículos van acompañados por un conjunto de crímenes individuales cometidos contra personas identificadas individualmente con nombre y apellido: secuestros, privaciones ilegítimas de la libertad, torturas y homicidios. Apelando al sentido común, los lectores conocen los delitos comunes que se enumeran. Si son estos los delitos por los que se realiza el proceso contra Etchecolatz, delitos que no merecerían ser explicados -sería redundante explicar qué es un secuestro o un homicidio-, queda pendiente un desarrollo en profundidad sobre los crímenes de lesa humanidad, categoría que englobaría a todos ellos.

Al avanzar cronológicamente en el análisis de las fuentes, no se encuentra un tratamiento sobre lo que implican estos crímenes, sino que una y otra vez los mismos son enunciados a partir de este conjunto de delitos individuales. No obstante, la falta de indagación, las descripciones son siempre a partir de este conjunto de crímenes individuales, por lo que es 
posible deslizar que para los tres diarios eso es lo que son los delitos de lesa humanidad: un conjunto de hechos de carácter individual. Aún así, y tomando en cuenta este conjunto de hechos individuales, tampoco hay análisis o descripciones que den cuenta de estos hechos de modo sistemático. No portan las mismas implicancias aquellos análisis que expresan que determinados delitos contra tales personas fueron cometidos por determinado imputado en determinado centro clandestino, que la contextualización de estos delitos de modo sistemático ubicando a los centros clandestinos como parte de una red a lo largo y ancho del territorio nacional, es decir como parte de un sistema amplio que no solo de cuenta de un lugar donde se cometieron determinados delitos sino como parte de una malla articulada $y$ fundamentalmente planificada.

Entonces, resulta primordial señalar esta doble característica de los delitos de lesa humanidad tal y como aparecen en los relatos periodísticos; en primer lugar, son descriptos a partir de delitos individuales; en segundo lugar, no aparece un marco de especificidad que dé cuenta de la sistematicidad de los mismos. Por último, surge una tercera característica y el trabajo de archivo demuestra que también es tratada de modo superficial; no se hace hincapié en que estos crímenes fueron cometidos por el Estado y que es esta es una de las particularidades por lo cual son imprescriptibles.

Al avanzar tres años en el proceso judicial, se encuentran las mismas regularidades discursivas sobre los crímenes, es decir las constantes entre los objetos, los tipos de enunciación, los conceptos, las elecciones temáticas (Foucault, 2007: 55). En este sentido, la acumulación de experiencia y de avance del proceso no parece dar cuenta de una acumulación en el desarrollo o la indagación de la constitución y las implicancias de los crímenes de lesa humanidad. Los mismos continúan siendo nombrados sin aclaraciones y tampoco se encuentran artículos abocados especialmente a la explicación de los mismos aún cuando mucha de esta información se encuentra disponible en los fundamentos de cada sentencia luego de finalizados los juicios.

En 2009, el archivo da cuenta de la misma constante, la escasa profundización sobre la "lesa humanidad". Los extractos que se presentan a continuación pertenecen a la cobertura del primer juicio por los crímenes cometidos en Campo de Mayo (6) y son alusivos a la línea que se viene tratando:

El victimario pretendió victimizarse, al menos durante el lapso que duró su declaración en la segunda audiencia del primer juicio por delitos de lesa humanidad cometidos en jurisdicción de Campo de Mayo (Página/12, 30/04/2009). 
El primero de los juicios por los crímenes de lesa humanidad cometidos en la guarnición de Campo de Mayo durante la dictadura comenzó hoy en el Tribunal Oral Federal $n^{\circ} 1$ de San Martín con el debate por el secuestro y asesinato de Floreal Avellaneda, un militante adolescente de tan solo 15 años (La Nación, 12/08/2009).

Como se observa, nuevamente "delitos de lesa humanidad" cometidos en un sitio determinado, Campo de Mayo; delitos de lesa humanidad que son el secuestro y asesinato de Floreal Avellaneda. Los ejemplos anteriores son una muestra significativa de las innumerables veces y modos en que es repuesta por los diarios la "lesa humanidad" en el período de diez años. Con una particularidad distintiva, lo mismo puede observarse en 2010 para el juicio al suboficial Gregorio Molina en Mar del Plata (7):

El fallo es inédito en el país, ya que contempla las reiteradas violaciones a dos detenidas como delitos de lesa humanidad (...). Es el primer fallo en el país que contempla las violaciones en sí, no comprendidas como parte de la tortura, como delitos de lesa humanidad. Sólo hay tres antecedentes en el mundo (Clarín, 10/06/2010).

El fallo quedará en la historia porque por primera vez la Justicia calificó como delito de lesa humanidad, diferente de las torturas, a las violaciones de secuestradas cometidas por integrantes de las Fuerzas Armadas (Página/12, 10/06/2010).

En el juicio "Molina", nuevamente se encuentra la calificación de lesa humanidad, junto a la enumeración de distintos delitos individuales, pero lo distintivo es que uno de estos delitos es la violación a secuestradas. Respecto a otros juicios, la diferencia de éste radica en que el tribunal considera a estas violaciones como delitos de lesa humanidad y no como parte de otros delitos como por ejemplo la tortura. Si bien los diarios resaltan lo inédito del fallo en Argentina debido a los pocos antecedentes en el mundo, no se explica por qué las violaciones constituirían un delito de lesa humanidad en sí mismas, nuevamente dando por sentado lo que son los delitos de este carácter. Además, es interesante el corrimiento de sentido que se realiza ya que a diferencia de todo el otro repertorio de delitos que constituirían los crímenes de lesa humanidad -donde simplemente se los enumera-, al finalizar este juicio se recupera el criterio del tribunal para el cual las violaciones serían delitos de lesa humanidad en sí mismos y no parte de los tormentos o las torturas. Sin embargo, el análisis carece del paso que falta para el armado de la explicación; a diferencia del resto de los delitos del repertorio -secuestro, torturas, homicidios- las violaciones son expresamente consideradas delitos de lesa humanidad, pero al igual que el resto de los hechos no hay una explicación que dé cuenta de 
su constitución como tal, qué es lo que determina que las violaciones sean de lesa humanidad sino únicamente se retoma y reproduce la sentencia del tribunal.

Lo mismo se observa en el segundo juicio de Campo de Mayo (8). Tanto Página/12 como La Nación dan cuenta de la misma caracterización, los delitos son de lesa humanidad. Además, pudiendo focalizar especialmente en el hecho de la responsabilidad estatal por ser Bignone un ex presidente de facto, esta arista no aparece. Un día antes de comenzar el juicio se halla en Página/12:

Reynaldo Benito Bignone, el general que ordenó incinerar los archivos de las Fuerzas Armadas sobre la guerra sucia y que confesó ante una periodista francesa que los desaparecidos "sólo fueron ocho mil", comenzará a ser juzgado mañana por el Tribunal Oral Federal 1 de San Martín por crímenes de lesa humanidad en Campo de Mayo, el mayor centro de torturas y exterminio del país durante la última dictadura" (Página/12, 2/11/2009).

Y el día de comienzo del juicio tras la primera jornada de audiencias el mismo diario publica en su portal digital con las noticias actualizadas:

El último presidente de la dictadura, Reynaldo Bignone, y otros ex generales que comandaron Campo de Mayo, comenzaron a ser juzgados ante el Tribunal Federal número 1 de San Martín, acusados de 58 secuestros, desapariciones y tormentos en esa guarnición militar (Página/12, 2/11/2009).

Al finalizar el proceso puede observarse nuevamente lo mismo:

La Secretaría de Derechos Humanos solicitó una pena de 25 años de prisión para el ex presidente del gobierno militar Reynaldo Bignone y para otros cinco imputados, en el marco del juicio por delitos de lesa humanidad. (...) Los seis ex militares y el ex policía están acusados como supuestos "autores mediatos" y "autores inmediatos", según cada caso, de allanamientos ilegales, tormentos y privaciones ilegales de la libertad en 26 casos de delitos de lesa humanidad contra 56 víctimas en los centros clandestinos de detención La Casita y El Campito, que funcionaron en Campo de Mayo (La Nación, 4/02/2010).

A los 82 años, luego de tres décadas impune, el último dictador pasó su primera noche en una cárcel común, condenado por crímenes de lesa humanidad. El Tribunal Oral Federal 1 de San Martín consideró a Reynaldo Bignone coautor de medio centenar de privaciones ilegales de la libertad y torturas, cometidas por sus subordinados de Campo de Mayo en 1977, cuando era jefe del Estado Mayor del Comando de Institutos Militares. (...) Menos 
pública era hasta ayer su actuación en 1977 en el Comando de Institutos Militares (CIM), organismo del que dependían los cuatro centros clandestinos que funcionaron en Campo de Mayo, por los que se estima pasaron cinco mil personas. El tribunal de San Martín condenó al dictador por once allanamientos ilegales, seis robos, cuarenta y cuatro secuestros y treinta y ocho tormentos. Gracias al método de la represión argentina de desaparición de personas, seguirá impune por los homicidios (Página/12, 12/04/2010).

Es interesante destacar que en los juicios donde la sentencia es por crímenes de lesa humanidad, no se problematiza la sistematicidad de los mismos, sino que se toma al discurso jurídico como un hecho y se enumera uno a uno los crímenes individuales por los que se juzga a los imputados. El caso de Bignone muestra este señalamiento ya que, si bien la calificación jurídica de la sentencia es por crímenes de lesa humanidad, los diarios hacen hincapié una y otra vez en los delitos individuales sin dar cuenta de la sistematicidad de los mismos ni problematizarlos como prácticas específicas de un plan sistemático. En este sentido, en el juicio a Patti (9) se encuentran las mismas descripciones en lo que hace al modo de dar cuenta de los crímenes, siempre son de lesa humanidad y el detalle sobre los mismos está compuesto por los delitos individuales al inicio del proceso y al finalizar el mismo (la negrita es propia y destaca los títulos):

Patti llegó en camilla para enfrentar el primer juicio oral por delitos de lesa humanidad ( $L a$ Nación, 24/08/2010).

Juicio por delitos de lesa humanidad. Perpetua en cárcel común para Patti El Tribunal Oral Federal N¹ de San Martín condenó al ex subcomisario y ex intendente de Escobar al hallarlo responsable de los delitos de allanamiento ilegal, privación ilegítima de la libertad, imposición de tormentos y homicidio (Página/12, 14/04/2011).

Comenzó el juicio contra Patti y Bignone por crímenes en Campo de Mayo

El ex comisario fue llevado en camilla a los tribunales. Junto al ex presidente de facto, son juzgados por un homicidio, nueve privaciones ilegítimas de la libertad y seis casos de torturas perpetrados durante la dictadura (Clarín, 15/04/2011).

Otra forma de nombrar a los delitos que se vincula íntimamente por sus implicancias a los crímenes de lesa humanidad es el concepto de terrorismo de estado que es utilizado por los diarios en contadas ocasiones. Si se atiende al significado de este concepto, los crímenes que cometería el estado terrorista son los mismos que todos aquellos implicados en los crímenes de lesa humanidad ya que no hay crónicas o artículos en los que se detalle qué implicaría el 
terrorismo sino que se utiliza meramente de modo descriptivo, como un sinónimo de lesa humanidad -y también de genocidio- acompañado de un compilado de delitos individuales que serían aquellos que por su comisión configurarían al estado en tanto "terrorista". Puede observarse a continuación:

El episodio fue denunciado hoy por María Isabel de Mariani, fundadora de Abuelas de Plaza de Mayo y mamá de Daniel Mariani, que fue víctima del terrorismo de Estado junto a su esposa, Diana Teruggi, y a quienes el gobierno bonaerense pretendía cobrarles una deuda de $\$ 1155$ pesos (Página/12, 7/07/2006).

Los relatos que reactualizan el tema tienen un doble valor adicional: pertenecen a ex conscriptos, testigos centrales del terrorismo de Estado que recién ahora sienten que cuentan con las garantías necesarias para hablar, y tuvieron lugar durante un juicio oral y público, ante un tribunal de la Nación y mirando a los ojos al imputado, un torturador y violador de mujeres secuestradas que perteneció a la Fuerza Aérea Argentina (Página/12, 24/05/2010)

A partir de los distintos ejemplos citados se intentó dar cuenta de la caracterización que resulta mayoritaria del análisis de las fuentes. Como se verá a continuación, que resulte mayoritaria y constituya el principal estereotipo de los delitos no significa que sea la que mayor alcance explicativo y simbólico posea.

\section{Genocidio}

La utilización del concepto genocidio ofrece una mirada y dimensiones muy distintas a la de crímenes de lesa humanidad. Si bien su uso en los periódicos es minoritario en contraste con los crímenes de lesa humanidad, los modos en que es descripto, las críticas, implicancias y discusiones que se vinculan al mismo le otorgan una superioridad analítica respecto a otros modos de calificar los cuales se utilizan de modo indiferenciado y sin una explicación previa, durante o después del proceso.

A diferencia de los crímenes de lesa humanidad, el concepto de genocidio no aparece en las crónicas desde el inicio de los juicios, sino por lo general luego del dictamen a favor por parte del tribunal. En estos casos, algunos diarios hacen propia la calificación retomándola e indagando al respecto, mientras que otros tan solo lo mencionan como información adicional sobre el cierre del proceso, ó directamente la critican. A diferencia de los otros modos de 
denominación, el uso del concepto de genocidio es polémico: cuando surge se retoma para explicarlo, apoyarlo o criticarlo ideológicamente pero nunca para darlo por sentado.

La emergencia del genocidio se configura de dos modos. En primer lugar, es introducido cuando las querellas solicitan su aplicación al tribunal en los alegatos, en segundo lugar, es presentada cuando el tribunal falla por la misma. Una tercera variable atraviesa estas dos modalidades: a diferencia de los crímenes de lesa humanidad el concepto de genocidio aparece de modo minoritario, pero suele ser explicado. Esta explicación se constituye a partir de la reposición textual de los alegatos de las querellas, luego del dictado de la sentencia detallando qué es, recalcando el hecho como histórico, publicando artículos a favor y en contra del mismo, incluyendo entrevistas a especialistas como jueces o académicos. Es decir, ante este concepto se encuentra un rasgo eminentemente explicativo. Estas características específicas del modo en que emerge y se narra el concepto de genocidio, refuerzan la hipótesis de que los crímenes de lesa humanidad se vinculan al sentido común, son conocidos por los lectores y no hace falta explicarlos siendo el genocidio algo novedoso y también polémico que debe ser desarrollado.

El juicio contra Miguel Etchecolatz es el primero en el que la sentencia ubica a los crímenes en el marco del genocidio. En el apartado anterior se vio como al inicio de este juicio los diarios trataban a los crímenes exclusivamente como "delitos de lesa humanidad"; promediando la finalización del juicio, este tratamiento sobrelleva un despegue ya que comienza a ser nombrado el genocidio. La primera vez que se encuentra esta caracterización es en una nota muy breve de Página 12 en la que se cita a una abogada querellante:

\begin{abstract}
La querella unificada de los organismos de derechos humanos planteará la violación a las detenidas como una de las prácticas sistemáticas del terrorismo de Estado, tal como revelaron los testimonios del proceso al represor Miguel Etchecolatz (...).Lo que se vio es que la mayoría de las detenidas fue violada sistemáticamente", explicó la abogada de Ceprodh, Myriam Bregman, quien explicó que "en todos los genocidios la violación existe como una marca que estigmatiza a la persona y sirve como medio para aterrar a la población (Página/12, 12/09/2006).
\end{abstract}

Esta primera vez en que el concepto aparece, no es esgrimido como una categoría propia sino que es una reinterpretación de la cita textual de Myriam Bregman: da cuenta de la violación como una práctica sistemática existente en todos los genocidios con un objetivo bien delimitado, aterrar a la población. Ante esta primera aparición, para Página/12 las violaciones son prácticas sistemáticas pero no del genocidio sino del terrorismo de Estado. Pero poco a poco la utilización del término irá mutando; otra vez en los últimos días de audiencias vuelve a 
aparecer la caracterización de los crímenes como genocidio. En esta oportunidad es presentado por los tres diarios a través de la reposición textual de la postura de los querellantes o el relato de sus pedidos:

\begin{abstract}
Los querellantes pidieron la condena a reclusión perpetua del ex mano derecha de Ramón Camps durante la represión ilegal y solicitaron que se lo acusara por genocidio. "No es una sumatoria de crímenes, sino un plan sistemático de exterminio", dijeron (Página/12, 19/09/2006).

El fiscal Carlos Dulau Dumm y los querellantes habían pedido, justamente, la reclusión perpetua para el ex comisario general por encontrarlo responsable de los delitos de homicidio agravado por ensañamiento y alevosía, privación ilegítima de la libertad y tormentos. La figura de "genocidio" incluida por el tribunal había sido solicitada por la querella (La Nación, 20/09/2006).
\end{abstract}

Este tramo final del proceso había comenzado horas antes, con los alegatos de los querellantes, que reclamaron que se aplique la figura de "genocidio" (Clarín, 18/09/2006).

El rasgo distintivo que se observa en las tres citas es que la figura de genocidio no es propia de la narrativa del diario, sino que es la narración de los pedidos de la querella. En la primera cita, Página/12 repone la acusación por genocidio no como una sumatoria de crímenes sino como un "plan sistemático de exterminio" que a la hora de hacer suyo el encuadre de los hechos los ubica en el marco de la "represión ilegal". A diferencia de los crímenes de lesa humanidad existe un cambio de enfoque en lo que refiere a la circunscripción de los delitos: aún cuando son relatados a partir de los pedidos de las querellas aparece la idea de un plan sistemático implementado para el exterminio y no como una sumatoria de crímenes. En la segunda y tercera cita se da cuenta de un elemento que en principio parece ser desconocido, cuestionable o polémico: cuando se narra el reclamo de los querellantes por la figura de genocidio, la palabra aparece entrecomillada. Estas comillas son expresión directa de la hipótesis que supone al genocidio como polémico. Se desliza esta conjetura ya que en el archivo no se han encontrado citas en las que los otros modos de denominar aparezcan entrecomillados; no hay "crímenes de lesa humanidad", "terrorismo de estado", "crímenes de la dictadura" y tampoco el "guerra sucia" pero si hay "genocidio". Este entrecomillado no es la primera ni la única vez que aparece; en 2007 luego de la condena a Von Wernich (10) y en 2011, finalizando el juicio a Luis Abelardo Patti por los crímenes que cometió en Campo de Mayo, se encuentran los siguientes ejemplos: 


\begin{abstract}
Ayer, el tribunal difundió los fundamentos de ese fallo y dejó en claro que las pruebas acumuladas dan cuenta de la participación acabada del sacerdote en los crímenes del terrorismo de Estado que los magistrados calificaron como "genocidio (Página/12, 7/11/2007).

El abogado Pablo Llonto pidió prisión perpetua para los represores acusados de los secuestros y asesinatos de Gastón Gonçalves y Diego Muniz Barreto. Hizo hincapié en el carácter de "genocidio" del plan sistemático aplicado por la dictadura (Página/12, 4/02/2011).
\end{abstract}

Lo distintivo de la precedente cita es que si bien el concepto no se reconoce como propio si se hace propia en la narrativa la idea de un plan sistemático de exterminio aplicado por la dictadura, que es uno de los objetivos fundamentales del genocidio y además esta idea no aparece entrecomillada. Pero el elemento más distintivo a resaltar sobre el uso de este concepto es el modo en que aparece luego de que los tribunales fallen a su favor. En estos casos resulta sugerente que los diarios hacen propio el concepto dando cuenta de una influencia del discurso jurídico por sobre el periodístico. En el siguiente apartado da cuenta de este efecto jurídico.

\title{
Los efectos del genocidio
}

Un hallazgo respecto al uso de genocidio es que cada vez que el concepto aparece produce efectos en las narrativas que pueden sintetizarse bajo tres modalidades: en primer lugar la incorporación del término como propio luego de leída la sentencia, en segundo lugar destacando la importancia de su utilización, tercero explicando detalladamente lo que constituye un genocidio a partir de la palabra de especialistas, y por último la introducción de la discusión y la polémica por su uso.

Dos cuestiones resultan importantes respecto de la incorporación del concepto de genocidio por parte de los periódicos: ninguna de estas modalidades tiene lugar en los casos en que las condenas son por crímenes de lesa humanidad y la incorporación del concepto no se da para siempre. Una vez que los diarios la retoman luego de las sentencias, no la continúan usando a lo largo de los siguientes procesos, sino que la figura pierde fuerza y se retoma la narrativa de los crímenes individuales y la lesa humanidad que constituyen el estereotipo hegemónico de los delitos. 
a. La incorporación de genocidio como categoría propia

Esta aparece de dos formas; la primera de de modo directo, cuando la figura aparece como parte del vocabulario del periódico sea para nombrar los crímenes o para describir alguna circunstancia vinculada (por ejemplo, dar cuenta del carácter de genocida del imputado); en segunda instancia de modo indirecto, cuando se hace propia la explicación de las implicancias del genocidio aún cuando este no sea incorporado como categoría propia, pero si es descripto en tanto proceso. En lo que refiere a la modalidad de incorporación directa las siguientes volantas y título de nota sirven de ejemplo:

Derechos Humanos: juicio contra un represor por crímenes de la dictadura Condenan a reclusión perpetua a Etchecolatz por genocida (Clarín, 20/09/2006)

Ex capellán de la Policía Bonaerense, partícipe del genocidio Von Wernich a juicio oral (Página/12, 19/12/2006)

El primero de los títulos con su respectiva volanta es del 20 de septiembre de 2006, un día después de la condena a Etchecolatz. En ella se pueden observar como aparece el adjetivo "genocida" calificando a Etchecolatz luego de haber sido leída la sentencia en la que se lo condeno por "delitos de lesa humanidad cometidos en el marco del genocidio que tuvo lugar en la Argentina entre los años 1976 y 1983" (11). El segundo de ellos pertenece a un artículo de Página/12 y se inscribe unos meses antes del comienzo del juicio al sacerdote represor Christian Von Wernich, en esta volanta se observa como en la inmediatez de los meses posteriores a la primer condena que ubicaba a los crímenes bajo la figura de genocidio, el mismo es incorporado en la narrativa como propio, de modo directo y dando cuenta de un proceso particular, que hasta ese entonces venía enmarcándose bajo "los crímenes de la dictadura", el "terrorismo de estado" o el mayoritario "crímenes de lesa humanidad". Un ejemplo mucho más gráfico de esta modalidad puede observarse en las tapas de Clarín y Página/12 del 20 de septiembre de 2006, el día siguiente a la condena de Etchecolatz: 



El segundo componente de esta modalidad, la incorporación indirecta puede ejemplificarse a partir de la siguiente cita:

Los jueces que condenaron a reclusión perpetua al ex capellán de la Bonaerense señalaron que por su condición de sacerdote tuvo un rol "específico" y "trascendente" en el plan criminal. Hablaron de genocidio (Página/12, 2/11/2007).

El extracto da cuenta del uso indirecto del concepto al narrar que los jueces "hablaron de genocidio" y se hace referencia al mismo en términos de plan criminal; se considera que hubo una planificación, lo que es un elemento fundamental de la implementación de un genocidio y en el que Von Wernich tuvo un rol específico y fundamental. Otros ejemplos concretos de esta modalidad "indirecta" es la ya analizada incorporación del concepto a partir del pedido o la reposición textual de la voz de los querellantes cuando solicitan la aplicación de la figura.

\section{b. La importancia del uso de genocidio}

Toda vez que la justicia condenó en el marco del genocidio se hallan narrativas tendientes a marcar el valor y lo inédito del hecho, esta circunstancia no acontece con los crímenes de lesa humanidad lo que fortalece la hipótesis de que ellos son conocidos por los lectores y en ese sentido no habría necesidad de reponer qué son. En paralelo, al ser el genocidio algo inédito precisaría ser resaltado y explicado dada su excepcionalidad. Este señalamiento resulta primordial dado que los primeros dos juicios que se desarrollan en la provincia de Buenos Aires 
(contra Etchecolatz y Von Wernich) tienen sentencias que ubican a los crímenes en el marco de esta figura. Ahora bien, hasta el momento de la sentencia la forma más usual de caracterizar a los crímenes por los diarios es la de lesa humanidad -categoría que en ningún momento es repuesta analíticamente-, pero una vez que emerge el genocidio el mismo debe ser desarrollado y resaltada la importancia de su aplicación aún cuando el relato hegemónico sostenido haya sido el de la lesa humanidad. Los siguientes extractos dan cuenta de esta circunstancia:

La condena a reclusión perpetua contra el represor Miguel Etchecolatz tuvo una amplia repercusión entre juristas, integrantes de organismos de derechos humanos y especialistas internacionales. "Es una verdadera lección para el mundo", aseguró el consejero de las Naciones Unidas para la prevención del genocidio, Juan Méndez, asesor del secretario general de la ONU, Kofi Annan (...) Uno de los puntos que más entusiasmó a los juristas fue el uso de la figura de genocidio por parte de los jueces del Tribunal Oral Federal 1 de La Plata. (Página/12, 21/09/2006).

La figura de "genocidio" reconocida anteayer, por primera vez, en la parte resolutiva de la condena contra el ex director de Investigaciones de la policía bonaerense Miguel Etchecolatz podría "allanar el camino para agilizar cientos de causas por delitos perpetrados durante la última dictadura militar". Esto cree el presidente del Tribunal Oral en lo Criminal Federal №1, Carlos Rozanski, que anteayer condenó a reclusión perpetua a Etchecolatz. El magistrado explicó que "el reconocimiento de la figura de genocidio no tiene antecedentes", en la jurisprudencia interna (La Nación, 21/09/2006).

Esta condena por genocidio a un cura que la jerarquía de la Iglesia siempre supo quién era y qué había hecho, hace desmoronar como un castillo de arena ya seca, ya áspera, el aparato discursivo moral de la Iglesia Católica, para la que también era mucho más cómoda la teoría de los dos demonios. Bien, desde la condena a Etchecolatz ya lo sabemos. Es la Justicia la que dice que no hubo guerra sucia sino genocidio (Página/12, 10/10/2007).

En el primero de los casos se da cuenta de la repercusión y entusiasmo que tuvo la utilización en el campo jurídico y de los organismos de derechos humanos. En la segunda cita se resalta a partir de la voz de uno de los jueces del tribunal que condenó a Etchecolatz que el reconocimiento de la figura no tiene antecedentes en la jurisprudencia interna. Finalizando, la última el último recorte remarca la importancia de que el culpable es un miembro de la Iglesia Católica remarcando el hecho de que fue genocidio y no guerra sucia. 


\section{c. La expertise sobre el genocidio}

En los dos casos en los que se aplica el genocidio en las sentencias aparecen explicaciones expertas y de los funcionarios judiciales que utilizaron la figura. En la cobertura al juicio a Etchecolatz, días después de la sentencia, Página/12 publicó una entrevista al juez Carlos Rozanski - presidente del tribunal- en la cual las preguntas giran en torno a la tipificación. La cita a continuación condensa los principales puntos de la definición de genocidio:

\section{- ¿Por qué consideraron que es aplicable la definición del genocidio a la Argentina?}

-En 2006, uno dice: masacraron un millón y medio de armenios y es el día de hoy que ni siquiera está reconocido. Esto muestra la resistencia de esto. Son cien años. El nazismo, sí, porque en números fueron seis millones. Pero tenemos que empezar a ver esto en su dimensión amplia: aquí se persiguió y se aniquiló a una parte de un grupo nacional. Esto lo define el genocida, el que decide aniquilar. No podemos tarifar la dimensión del genocidio: "Si es menos de un millón, no es genocidio". Esos homicidios en la Argentina en el marco de una política de exterminio son un genocidio. Está demostrado: lo dijo (el juez español Baltasar) Garzón, lo dijo la Audiencia Nacional de España. Es importante que se llamen las cosas por el nombre correcto, y en los casos de violaciones a los derechos humanos no llamar las cosas por el nombre correcto demora treinta años la justicia. El genocidio se tiene que llamar genocidio (Página/12, 1/10/2006).

Lo fundamental en términos explicativos del recorte es que la dimensión de un genocidio no puede sostenerse en la cantidad de víctimas sino en la decisión de aniquilar parte de un grupo nacional en el marco de una política de exterminio. En este mismo sentido se puede citar la entrevista realizada por este mismo diario al sociólogo Daniel Feierstein donde también se da cuenta de la intención -decisión en la entrevista anterior- de destruir a un grupo social:

La diferencia del concepto de genocidio con respecto a cualquier otro concepto jurídico, incluido el de crimen de lesa humanidad, es que da cuenta de la intención específica, que es la destrucción de un grupo social. Es la única figura del Derecho Penal que no refiere a acciones cometidas contra individuos o sumatorias de individuos, sino a acciones cometidas contra grupos. El sentido central de la utilización del término genocidio es poder comprender que los efectos del aniquilamiento se proyectaron al conjunto de la sociedad, al grupo nacional argentino (Página/12, 4/11/2007).

En conclusión, es a partir de la mirada experta que se explica y profundiza sobre qué es el genocidio y quizá es esta característica, la necesidad de tener que explicarlo lo que lo constituye en la figura polémica que se desarrolla a continuación.

Question, Vol. 1, N. ${ }^{\circ}$ 63, julio-septiembre 2019. ISSN 1669-6581

Instituto de Investigaciones en Comunicación | Facultad de Periodismo y Comunicación Social | Universidad Nacional de La Plata 


\section{d. Una figura polémica}

Uno de los usos del genocidio que puede inferirse en tanto polémico es cuando el mismo aparece entrecomillado. Ahora bien, hay otros usos que exceden a esta utilización. El más distintivo de ellos se da cuando las narraciones discuten de modo directo la aplicación de este término sea a partir de argumentos propios o citando voces afines a los genocidas. El caso más paradigmático de esta modalidad se da en el juicio a Christian Von Wernich y se encuentra en las crónicas del diario La Nación. Tal es el caso que una vez dictada la sentencia se encuentra la siguiente apreciación: "Ayer, tanto la querella como el fiscal habían solicitado la reclusión perpetua para el sacerdote "por genocidio", figura que no estaba contemplada en la acusación inicial por "homicidios, torturas y privaciones de la libertad" (La Nación, 9/10/2007).

Esta postura luego se ve reforzada por el editorial de Bartolomé Mitre y las definiciones de Bignone en la misma línea:

En primer término, no se puede perder de vista el hecho de que la sentencia marca la culminación de un proceso judicial en el que se juzgaron "delitos de lesa humanidad cometidos en el marco del genocidio que tuvo lugar en la Argentina", según lo reconoce el propio tribunal en su fallo, con un lenguaje que, aunque discutible en algunas de sus variables terminológicas, desnuda el significado político y hasta ideológico de los sucesos que se han juzgado (La Nación, 11/10/2007).

Se nos tilda de represores y genocidas. En principio, el término represión no es descalificante: la autoridad tiene el deber de reprimir los delitos de cualquier tipo. Y lo de genocida no resiste el menor análisis porque lo ocurrido en nuestro país no se ajusta en lo más mínimo a la definición internacional del delito de genocidio, sólo voceros del odio pueden sostener esto", había señalado (La Nación, 20/04/2010).

En el primero de los ejemplos la polémica del término se lo define a partir de su falta de objetividad por tener una carga política e ideológica a la hora de juzgar los hechos. En el segundo de ellos el carácter polémico de la aplicación de genocidio está dado por su mala aplicación, es decir por no ajustarse a los acontecimientos perpetrados en el país.

\section{Palabras finales}

El artículo analizó los distintos estereotipos que emergieron del archivo periodístico respecto a los delitos: los crímenes de lesa humanidad y el genocidio. En estas caracterizaciones se 
pusieron en juego, por un lado, las lógicas individuales de la responsabilidad, y por otro, lógicas de comprensión más integrales de los crímenes cometidos por el estado.

El principal hallazgo respecto a los crímenes de lesa humanidad lo constituyó el hecho de ser el modo mayoritario de denominar a los delitos a lo largo de los diez años por los tres periódicos. Otro hallazgo lo constituyó el hecho de no haber encontrado publicaciones en las que se reponga o explique qué constituyen estos delitos dando por sentado lo que son como si fueran fenómenos conocidos por los lectores. El modo en que es descripto este estereotipo es a partir de un triple abordaje: en primer lugar, son descriptos a partir de delitos individuales secuestros, torturas, homicidios, etcétera-, en segundo lugar, no se halló un marco o contexto que dé cuenta de la sistematicidad de estos delitos individuales; por último, tampoco se da cuenta de que estos crímenes fueron cometidos por el estado.

El segundo estereotipo que se abordó es el de genocidio, se resaltó que el mismo no aparece en las crónicas desde el inicio de los juicios, sino que surge luego del dictamen a su favor por parte del tribunal, cada vez que es enunciado por el derecho y no antes. Aquí se puede delimitar una hipótesis performativa del discurso jurídico sobre el periodístico sobre el cual produce determinados efectos. Se señaló que Página/12 y Clarín retomaron la calificación como propia y en La Nación apareció una crítica respecto a su uso, en todas las modalidades en las que apareció siempre se explicó qué es un genocidio. Por ello se postuló a este estereotipo como polémico ya que todas las veces que los diarios hicieron uso del mismo debieron retomarlo ya sea para explicarlo, apoyarlo o criticarlo, pero nunca darlo por sentado. Respecto a este no dar por sentado se señaló que constituye un rasgo eminentemente explicativo del que es portador este concepto cuando aparece. A su vez esta modalidad explicativa reforzó la hipótesis de que los crímenes de lesa humanidad son conocidos por los lectores y no hace falta explicarlos y el genocidio es un concepto tanto novedoso como polémico y por ello debe ser repuesto. Esta última hipótesis que propone al genocidio como polémico también se vio corroborada a partir del uso del término entrecomillado: "genocidio".

Otra variable importante a la hora de analizar crímenes cometidos por el estado resultó ser la sistematicidad con que fueron cometidos los mismos. El trabajo de archivo demostró que no existe un análisis sistemático o exhaustivo sobre la sistematicidad y planificación, sino que en el estereotipo de lesa humanidad se da en términos de la enumeración de los delitos y en el caso de genocidio se da en términos de "plan sistemático" sin una reconstrucción sobre los elementos constitutivos de tal plan: en este sentido, la sistematicidad aparece pero no es explicada. 
Notas

(1) Se comprende al genocidio desde la perspectiva de Feierstein $(2007,2012)$, como una tecnología de poder que a partir del exterminio de una parte de la sociedad tiene como objetivo reorganizar a la sociedad en su conjunto a partir de la destrucción de las relaciones de autonomía y solidaridad encarnadas por los cuerpos aniquilados.

(2) Estas dos leyes son conocidas como "leyes de impunidad". Fueron sancionadas durante el gobierno de Raúl Alfonsín luego del Juicio a las Juntas (1985) y pusieron un coto a las responsabilidades de las fuerzas armadas y de seguridad limitando las posibilidades de juzgamiento.

(3) Se entiende estereotipo a partir de la concepción de Mailló Salgado (1980), como el soporte de los valores en un momento histórico determinado, configurando una cosmovisión de época.

(4) Si se traslada a los desarrollos académicos el modo en que los periódicos tratan a estos delitos se encuentra una similitud. A diferencia del campo de los estudios sobre genocidio donde se encuentra una prolífera producción y discusiones que se renuevan, no hay muchos trabajos académicos sobre los crímenes de lesa humanidad. Este escenario académico en el que poco se ha pensado a los crímenes de lesa humanidad es fundamental a la hora de analizar el hecho de que en los diarios tampoco se analice ni contextualice a los mismos. Se puede hipotetizar que son debates que ni siquiera se abrieron profundamente en los campos que mayor incidencia tienen en los procesos de juzgamiento que son los desarrollos jurídicos y académicos al respecto.

(5) En este juicio se juzgó al represor Etchecolatz por delitos cometidos contra 14 víctimas. Etchecolatz ofició el cargo de Director de Investigaciones de la Policía de Buenos Aires entre 1976 y 1977 siendo la mano derecha del jefe de la policía de la provincia. Fue condenado a prisión perpetua por homicidio calificado, privación ilegítima de la libertad y tormentos. Este juicio es el primero que incluye en su sentencia la figura de genocidio. En el marco de las audiencias del juicio; Jorge Julio López que en calidad de sobreviviente aportó información que involucraba directamente a Etchecolatz en la comisión de los delitos. El 18 de septiembre de 2006, a poco de finalizar el juicio, el día de la lectura de los alegatos López fue desaparecido por segunda vez y al día de la fecha no hay datos certeros sobre su paradero.

(6) Campo de Mayo es una guarnición militar en la que durante la dictadura militar funcionó uno de los principales campos de concentración y exterminio de personas, El Campito. El hospital militar ubicado en la misma locación también funciono como centro para la represión clandestina. El primer juicio por los crímenes cometidos en Campo de Mayo tomó el caso de Floreal Avellaneda y su madre Iris Pereyra, quienes luego de ser secuestrados en abril de 1976 
fueron llevados a la comisaría de Villa Martelli donde fueron torturados. Luego Iris Pereyra fue trasladada al Campito recuperando la libertad en 1978. Floreal Avellaneda fue asesinado y su cuerpo fue hallado en las costas de Uruguay en mayo de 1976.

(7) En este juicio se condenó al suboficial de la fuerza aérea Gregorio Molina por delitos cometidos contra cuarenta víctimas, dentro de ellas el homicidio de dos abogados de la ciudad de Mar del Plata. Fue el primer proceso en el que se responsabilizó al imputado por delitos sexuales, considerando los mismos como prácticas dentro de un plan sistemático de represión, como delitos de lesa humanidad.

(8) En este juicio se juzgó a siete imputados por delitos cometidos contra 58 víctimas. En éste recibió su primera condena el general Reynaldo Benito Bignone, el último de los presidentes de facto de la dictadura militar.

(9) El juicio contra Luis Patti constituye el tercer proceso por los crímenes cometidos en Campo de Mayo. Fue comisario en la comisaría de Escobar durante la dictadura, en el juicio fue juzgado junto a otros cuatro represores por los delitos de privación ilegítima de la libertad, tormentos y homicidios calificados.

(10) Su único imputado fue Cristian Von Wernich un sacerdote de la Iglesia Católica Argentina que era capellán de la policía de la provincia de Buenos Aires durante la dictadura. En ese rol ofició de interrogador y torturador. Fue condenado a prisión perpetua por los delitos de privación ilegal de la libertad, tortura y homicidios calificados incluyendo la sentencia la figura de genocidio.

(11) Fallo resolutorio de la causa 2251/6, Tocf Nro. 1, La Plata.

\section{Bibliografía}

Feierstein, D. (2007). El genocidio como práctica social. Entre el nazismo y la experiencia argentina. Buenos Aires: FCE.

Feierstein, D. (2012). Memoria y representaciones. Sobre la elaboración del genocidio. Buenos Aires: FCE.

Foucault, M. (2004). La arqueología del saber. Buenos Aires: Siglo XXI.

Maillo Salgado, F. (1980). Un análisis del discurso histórico: La ideología (lección teóricometodológica). Salamanca: Imprenta Comercial Salmantina.

\section{Notas periodísticas}


Clarín (22/06/2006). Se cumplió la primera jornada de declaración de testigos en el juicio a Etchecolatz. Recuperado de https://www.clarin.com/ultimo-momento/cumplio-primerajornada-declaracion-testigos-juicio-etchecolatz $0 \mathrm{rkrG} 4 \mathrm{cNkRYx}$.html

Clarín (18/09/2006). La fiscalía pidió reclusión perpetua para el represor Etchecolatz. Recuperado de https://www.clarin.com/ultimo-momento/fiscalia-pidio-reclusionperpetua-represor-etchecolatz 0 ryQZHK7kRK1.html

Clarín (20/09/2006). Condenan a reclusión perpetua a Etchecolatz por genocida. Recuperado de $\quad$ https://www.clarin.com/ediciones-anteriores/condenan-reclusion-perpetuaetchecolatz-genocida 0 By9xzYm10Fg.html

Clarín (10/06/2010). Noche de las corbatas: condena a cadena perpetua. Recuperado de https://www.clarin.com/politica/Nochecorbatascadenaperpetua $0 \quad 2777772250 . \mathrm{html}$

Clarín (15/04/2011). Represión ilegal: condenan a Patti a perpetua en una cárcel común. Recuperado de https://www.clarin.com/politica/RepresionilegalcondenanPattiperpetua $0 \quad 463153730 . h t$ $\underline{\mathrm{ml}}$

La Nación (20/06/2006). Finalizó la primera jornada del juicio oral contra Etchecolatz. Recuperado de https://www.lanacion.com.ar/816335-finalizo-la-primera-jornada-deljuicio-oral-contra-etechecolatz

La Nación (20/09/2006). Condenaron a prisión perpetua a Etchecolatz. Recuperado de https://www.lanacion.com.ar/841991-condenaron-a-prisión-perpetua-a-etechecolatz

La Nación (21/09/2006). La figura del genocidio. Recuperado de https://www.lanacion.com.ar/842239-la-figura-del-genocidio

La Nación (9/10/2007). Reclusión perpetua para Von Wernich por genocidio. Recuperado de https://www.lanacion.com.ar/951500-reclusion-perpetua-para-von-wernich-porgenocidio

La Nación (11/10/2007). El juicio a Von Wernich. Recuperado de https://www.lanacion.com.ar/952006-el-juicio-a-von-wernich

La Nación (12/08/2009). Perpetua para el represor Riveros por el crimen de Floreal Avellaneda. Recuperado de https://www.lanacion.com.ar/1161705-perpetua-para-el-represorriveros-por-el-crimen-de-floreal-avellaneda

La Nación (4/02/2010). Pidió el estado 25 años de prisión para Bignone por delitos de lesa humanidad. Recuperado de https://www.lanacion.com.ar/1229454-pidio-el-estado-25años-de-prision-para-bignone-por-delitos-de-lesa-humanidad 
La Nación (20/04/2010). Pidió el estado 25 años de prisión para Bignone por delitos de lesa humanidad. Recuperado de https://www.lanacion.com.ar/1229454-pidio-el-estado-25años-de-prision-para-bignone-por-delitos-de-lesa-humanidad

La Nación (20/04/2010b).La justicia condenó a Reynaldo Bignone a 25 años de prisión común. Recuperado de https://www.lanacion.com.ar/1256326-la-justicia-condeno-a-reynaldobignone-a-25-años-de-prision-comun

La Nación (24/08/2010). Pospusieron un mes el juicio oral contra Patti. Recuperado de https://www.lanacion.com.ar/1297596-pospusieron-un-mes-el-juicio-oral-contra-patti

Página/12 (20/06/2006). Etchecolatz no declaro y quiere un tribunal militar. Recuperado de https://www.pagina12.com.ar/diario/ultimas/20-68741-2006-06-20.html

Página/12 (7/07/2006). El Estado me mató a mi único hijo, asesinó a mi única nuera, exige deudas inexistentes. Recuperado de https://www.pagina12.com.ar/diario/ultimas/2068741-2006-06-20-69589-2006-07-07.html

Página/12 (19/09/2006). Una tardía reparación del horror. Recuperado de https://www.pagina12.com.ar/diario/elpais/1-73218-2006-09-19.html

Página/12 (21/09/2006). Un fallo considerado como una "verdadera lección para el mundo". Recuperado de https://www.pagina12.com.ar/diario/elpais/1-73310-2006-09-21.html

Página/12 (1/10/2006). El juicio fue la suma de la historia. Recuperado de https://www.pagina12.com.ar/diario/elpais/1-73818-2006-10-01.html

Página/12 (19/12/2006). Von Wernich a juicio oral. Recuperado de https://www.pagina12.com.ar/diario/ultimas/20-77941-2006-12-19.html

Página/12 (10/10/2007). Nada banal. Recuperado de https://www.pagina12.com.ar/diario/elpais/subnotas/92760-29479-2007-10-10.html

Página/12 (2/11/2007). Fue un torturador calificado. Recuperado de https://www.pagina12.com.ar/diario/elpais/1-93982-2007-11-02.html

Página/12 (4/11/2007). La Justicia es discurso de verdad. Recuperado de https://www.pagina12.com.ar/diario/elmundo/4-94049-2007-11-04.html

Página/12 (30/04/2009). Uno que busco despegarse. Recuperado de https://www.pagina12.com.ar/diario/elpais/1-124160-2009-04-30.html

Página/12 (2/11/2009). Bignone el último presidente de la dictadura. Recuperado de https://www.pagina12.com.ar/diario/elpais/1-134545-2009-11-02.html

Página/12 (2/11/2009b). Comenzó el juicio al último dictador. Recuperado de https://www.pagina12.com.ar/diario/ultimas/20-134550-2009-11-02.html

Página/12 (12/04/2010). Primera noche en una cárcel común. Recuperado de https://www.pagina12.com.ar/diario/elpais/1-144286-2010-04-21.html 
Página/12 (24/05/2010). Subían a las personas esposadas o maniatadas. Recuperado de https://www.pagina12.com.ar/diario/elpais/1-14263-2010-05-24.html

Página/12 (10/06/2010). Represor con perpetua. Recuperado de https://www.pagina12.com.ar/diario/elpais/1-147292-2010-06-10.html

Página/12 (14/04/2011). Quisieron que el miedo nos paralizara. Recuperado de https://www.pagina12.com.ar/diario/elpais/1-161691-2011-02-04.html

Página/12 (14/04/2011b). Perpetua en cárcel común para Patti. Recuperado de https://www.pagina12.com.ar/diario/ultimas/20-166251-2011-04-14.html 